\title{
FIDELINO DE FIGUEIREDO (Homenagem) *
}

Ao ensejo deste II Encontro Internacional de Camonistas, em que ainda ressoam os ecos das comemorações camonianas de 72, não podia haver idéia mais feliz do que reverenciarmos a memória de Fidelino de Figueiredo, sempre cara e permanentemente viva no espírito daqueles que tiveram o condão de conhecê-lo e conviver com ele.

Nas suas deambulações pelo mundo - como autêntico português que foi - durante 14 anos Fidelino pregou a sua atividade magistral nas duas Faculdades de Filosofia recém-criadas no Brasil - a da Universidade de São Pau'o e a antiga Nacional de Filosofia da Universidade do Brasil. Nos anos de 1938-39 integrava o corpo docente da primeira, quando em fins de 39, convidado por Alceu Amoroso Lima, passou a lecionar na segunda, de onde regressou, dois anos depois, para se fixar de novo e definitivamente na Universidade de São Paulo. Nas duas Faculdades plantou Fidelino a sua doutrina, e colheu os frutos de sua pregação, formando discípulos como Celso Cunha, Carlos Assis Pereira, Jesus Belo Gavão, Gladstone Chaves de Melo, Cleonice Berardinelli, Antônio Soares Amora e tantos outros.

As duas instituições lhe devem, portanto, uma gratidão imorredoura, pelo amor e pela inte'igência com que presidiu aos primórdios da nossa vida universitária. E neste momento se cumpre, merecidamente, o dever de saldar esse tributo.

Se nos fosse permitido escrever algumas páginas de nossas memórias (e quem ultrapassa a casa dos 50 já se sente com o direito e com a vocação para a autobiografia), e alguém nos apresentasse inopinadamente um questionário com estas perguntas: qual o mes-

$\left(^{*}\right)$ - Alocução proferida no auditório do Gabinete Portuguêes de Leitura do Rio de Janeiro, em 13 de novembro de 1973, por ocasião do Congresso Internacional de Filolofia Portuguesa e da II Reunião Internacinnal de Camonistas, promovidos pela Universidade Federal Fluminense e pela Fundação Casa de Rui Barbosa. Nesta sessão foram cultuadas, em homenagem especial, as memórias de Afrânio Peixoto, Fidelino de Figueiredo e Thiers Martins Moreira. 
tre que mais contribuiu para a sua formação? Qual a obra que mais o impressionou? A lição que mais se fixou no seu espírito? - não teríamos hesitação em responder: esse homem que marcou a nossa biografia mental (bem como a da minha geração) foi sem dúvida - mestre de Alvalade; a obra que teve o condão de fecundar o nosso espírito para a primeira tese de grau, foi $A$ luta pela expressão; a lição que se insculpiu de forma indelével em nossa vida profissional foi a de que devemos sempre superestimar o nosso labor intelectual. E se nos perguntassem ainda qual o sortilégio que envolve esta obrasita de 150 páginas: a sua erudição? Acaso o tratamento profundo do fenômeno literário? A densidade de sua doutrina? - responderíamos que nada disso. O livro, despretensioso ensaio sobre a guerra dos homens com as palavras e apenas um preliminar para a filosofia da literatura, foi o núcleo e a pataforma de encontro num curso de especialização que em 1946 professou o Mestre, na Faculdade de Filosofia, a propósito da ciência literária. E a primeira lição que daí se tirou foi a angustiante consciência das limitações de nossos conhecimentos; um quase trauma, advindo do preparo inte'octual com que contávamos e as exigências de trabalho que se impunham. Leituras prévias de obras como a Crítica da razão pura de Kant, a Criteriologia de Mercier e outras desse tipo, colocavam em xeque a candura filosófica de um punhado de bacharéis, recém-egressos das Letras e em estado de pureza quase absoluta no campo da reflexão. A corroborar a nossa imaturidade, faltava-nos aquele mínimo de cultura filosófica que ainda hoje os cursos superiores de letras não transmitem. Bem ou mal (um ba anço talvez acusasse o segundo termo da alternativa), cumprimos a etapa. Ficou-nos a lição, porém: uma consciência aguda da imposs.bilıdade da formação do espírito crítico sem uma iniciação filosófica em geral, e estética em particular

Era talvez a primeira geração no Brasil a entrar em contacto com aquelas maciças teses do grupo de Ermatinger a propósito dos problemas filosóficos ou gnoseológico-metodológicos da ciência literária, temperados pela reflexão pessoal de quem viveu debluçado quase 50 anos sobre o conhecimento do fenômeno literário. Quase meio século, sim: "em 1912, fé devotada no método científico para construir a história literária ( $A$ crítica literária como ciência); em 1918, dúvidas sobre a rigidez objetiva da crítica e ane'os de uma valorização maior do trabalho crítico ("criação e crítica literária", em Estudos de literatura, 2. ${ }^{\mathrm{a}}$ série); em 1939. cisão franca do trabalho crítico da literatura e direção do espírito, tão livre e criadora como a inspiração poética (Aristarcos); em 1941, transformação completa do conceito de literatura e do conceito de crítica, para os ver de mais alto, como sublimações de traços elementares e constantes do espírito humano - o seu esforço de compreensão e a 
sua luta pela expressão (em "Defensão da Literatura", em Uitimas aventuras); em 1944, os prolegómenos para uma filosofia da literatura, com que supunha cerrar a trajetória teórica de um "doente da crítica' ( $A$ luta pela expresssão); em 1957, confiança na possibilidade de atingirmos uma criteriologia do fato literário ("Sobre criteriologia literária" na Revista da Faculdade de Letras de Lisboa, miscelânea de estudos em homenagem ao Prof. Hernani Cidade), - eis toda uma odisséia da inte igência crítica, que a metáfora afetiva de uma dedicatória de $2 .^{\text {a }}$ edição procurou transformar em desengano: "A Sigismundo, com saudades do tempo em que lhe impingia estas loas. " (Lisboa, 1960)

Para complementar esta pequena divagação em primeira pessoa, permitam-me recordar um fato, que dá bem a medida da grandeza de alma e do entranhado sentimento de responsabilidade moral do saudoso Mestre. $\mathrm{Na}$ tarde de 29 de outubro de 1950, ao entrarmos no salão nobre da Faculdade para enfrentar a banca examinadora de doutoramento, já ocupava a mesa o Professor Fidelino, aguardando os demais componentes do júri. Ali permaneceu durante seis horas dirigindo os trabalhos daquele ato universitário, sem reve'ar a ninguém a mínima demonstração de que havia sido arrancado do seu leito e carregado pelo filho para o $3 .^{\circ}$ andar da Faculdade, doente que estava de uma violenta queda sofrida na véspera. Era o primeiro aviso da dolorosa e implacável doença que dois anos depois havia de levá-lo irremediavelmente para Portugal, de onde nunca mais regressaria.

Muito e muito se teria por dizer de 'Fide'ino de Figueiredo; muitos já disseram, mas muitos haverão ainda de dizer Entretanto, as circunstâncias deste momento nos obrigam a fazer um corte na sua tão rica e complexa biografia, para extrairmos dela apenas um tema com que justificar esta homenagem. E mais uma vez peço licença para relembrar escritos meus, de abril de 1967, a propósito de suas contribu:ções para o campo da Camonologia.

O dia em que se fizer a história de um dos mais extraordinários espíritos que já iluminaram o pensamento luso-brasileiro neste século, no curso dessa longa e multímoda trajetória se desenvo've - com marcos muito nítidos - uma outra história: a da especulação camoniana. Camões, como não podia deixar de ser, foi tema de suas indagações críticas, desde os longínquos anos de 1910, quando, aos 21 anos, na sua História da crítica literária em Portugal inseria um capítulo a propósito da exegese camoniana no século XVII. Fidelino não vinha inspirado ainda pela idéia de uma filosofia do renascimento português. A importância dessas primẹiras páginas a respeito dos patriarcas da Camonologia estava no relevo que 
atribuia à crítica do primeino censor dos apologistas de Camões: Manuel Pires de Almeida, cuja obra fora desconhecida até 1955, e naquela época apenas suspeitada através dos testemunhos de João Soares de Brito (com quem manteve polêmicas Manuel Pires de Almeida) e de Diogo Barbosa Machado na sua Biblioteca Lusitana. Tentando reconstituir as linhas fundamentais da posição exegética do Licenciado Manuel Pires de Almeida, na acesa po êmica em torno do sonho de D. Manuel, Fidelino de Figueiredo chamou a atenção dos investigadores para a importância da revelação dos trabalhos desse autor, cujo ineditismo se quebrou quando Antônio Soares Amora, em 1950, conseguiu fotografar os manuscritos do $\mathrm{Li}$ cenciado, em Muge, na Biblioteca da Família do Cadaval.

Entretanto, as especulações em alto nível à volta da matéria camoniana, para sermos mais precisos, situam-se entre os dois grandes exílios sofridos por Fidelino: o exílio da pátria, na altura de 30, e o exílio do mundo nos anos de 52-53. Na amargura do primeiro a sua palavra falada peregrinou por vários recantos do mundo numa pregação de sua poderosa inteligência; no recolhimento do segundo, confinado às quatro paredes de sua Biblioteca no A:valade, a palavra escrita registrcu o mais dramático depo-mento de um espírito torturado pelos problemas transcendentes do Homem. Foi em meio aos percalços destes dois pungentes exílios que Fidelino de Figueiredo, sempre fustigado pela idéia de escrever uma monografia acerca da singularidade do quinhentismo português, se debluçou sobre a obra do maior poeta épico moderno. E perseguido, então, pela idéia de uma nova interpretação da renascença portuguesa, que o levaria a fixar um novo rumo às fontes da epopéia camoniana, F.F escreveu, para a História da literatura portuguesa iiustrcda (dirigida for Albino Forjaz de Sampaio), em 1930, já em meio às prime.ras horas amargas de seu exílio para Madri, um esboço desse sonho que alimentou depois por mais de 20 anos: um capítulo acerca dos épicos portugueses posteriores a Camões. Em Madri reelaborou a sua monografia incipiente já à luz de novas pesqu sas, pesquisas essas que depois continuaram na opulenta $\mathrm{Bi}$ b'ioteca da Columb:a University - para onde foi ensinar literatura portuguesa; de regresso à pátria em 1931, algumas semanas de iso amento em Cascaes lhe permitiram uma nova redação do seu estudo (publicada na coleção portuense de Estados Nacionais), complementada logo a seguir quando novamente em Madri o governo permitia acesso ao Palácio Real e propiciava ao Mestre novos e importantes elementos sobre as tapeçarias de estilo luso-indano; com isso foi enriquecendo a parte documental de suas investigações e reforçando a sua tese acerca do quinhentismo português. Em 1938, já à testa da Cadeira de Literatura Luso-Brasileira e inaugurando as publicações da Seç̧ão de Letras da Facu dade de 
Filosofia da USP, publicou a sua monografia com os apêndices documentares. F.F ainda continuava adiando a realização final da grande empresa, quando em 1947, numa primavera que ele diz amarga em sua terra, logrou chegar à redação definit,va do seu trabalho, que publica ainda pela Faculdade de Filosofia, em 1950, com o títu o "A épica portuguesa no século XVI (Subsídios documentares para uma teoria geral da epopéia) A fatalidade que o levou para o segundo exílio parecia haver estipulado o prazo final para a realização de sua grande obra. Fidelino acreditava poder, com este acervo documental aglutinado ao longo de vinte anos de pesquisa apaixonada, contribuir para o estabelecimento de uma teoria geral da epopéia, segundo o método que ele considerava realista, e método que norteara o seu espírito desde os anos de 1930: o de Joscph Bédier, que naquela década revolucionava as idéias vigentes sobre o gênese da épica românica. Ainda que o Mestre de Alvalade sempre acnsiderasse um "ovo de Colombo" as suas idéias a respeito do quinhentismo português, desenvolvidas ao longo destes 20 anos, devia ter consciência dos caminhos que abria; talvez não suspeitasse a abertura de uma nova etapa no terreno da Camonologia. "Passei boa parte da minha vida - diz ele - a ensinar Camões por universidades estrangeiras, a tentar a difíci' empresa de salientar o significado humano e renascentista da epopéia de Camões. Ele me acompanhou em exílios compulsórios e voluntários. Tinha de levar a cabo esta mal-aventurada monografia, que é como palma votiva deposta no pé do monumento do altíss.mo poeta"

Preito rendido, a repercussão de suas idéias não correspondeu à expectativa. Duas razões encontramюs que podem explicar a limitada ressonância de sua obra (que está a exigir uma segunda edição): a tiragem diminuta do trabalho, cuja distribuição, feita pe'o Autor, se circunscreveu a um círculo muito restrito de intelectuais e amigos; mas, acima destas contingências de ordem puramente editorial e afetiva, prevaleceu uma, de natureza metodológ.ca: se o Autor logrou demonstrar em que sentido Camões realizou a síntese dos valores formais com os valores espirituais do Renascimento; se com magistral poder de intuição reviveu a ambiência heróioa $e$ mítica do período joanino e manuelino em todas as suas formas (o preceptorado dos humanistas ita ianos, as relações epistolares entre D. João II e Policiano, a febre heróica tecida nas famosas colgaduras luso-indianas, a mesma febre na obra dos Cronistas, a repercussão do apostolado marítimo português na pintura de artistas italianos como Miguel Ângelo etc. etc.), com monumental independência de espírito não deixou de assinalar também o descontentamento anti-heróico, o reverso da medalha, canto de cisne de toda uma grandeza épica que teve o seu momento de declínio e um cor- 
tejo de aspectos negativos. A postura científica que sempre orientou os trabalhos do crítico na investigação histórica e literária, e a coragem mental de apontar a verdade quando necessário, sempre foram notas pouco simpáticas a um provincianismo estreito e a um jacobinismo esclerosado que se alimenta ainda das grandezas do passado. A épica camoniana não era apenas a expressão dessa ufania heróica, desse sentimento de superação da própria antiguidade clássica, dessa dominação da distância e das forças adversas da $\mathrm{Na}$ tureza bruta e até então indominada: era também o retrato de "uma apagada e vil tristeza" que ao tempo do Poeta se desenhava e com cores carregadas; não era apenas uma história de Gigantes Adamastores vencidos pela intrepidez da gente lusa: era também o registro amargo dos Velhos de Restelo e da consciência tridentina de que o homem é um "b.cho da terra tão pequeno" Ninguém, até então, se lembrara de fotografar o outro lado da história de Quinhentos.

Recolhido compulsoriamente ao seu recanto do Alvalade, para viver agora as dores mais profundas do seu segundo exílio, Fidelino continuou a refletir sobre o velho tema camoniano, e o fruto destas últimas disquisições traz o timbre da serenidade intelectual, da experiência amadurecida ao longo desta peregrinação de duas décadas, talvez até a consciência de uma analogia com a vida do Poeta. E o período das suas Variações sobre o espírito épico, uma tentativa final para situar no plano universal to poema camoniano. "A Renascença foi um grande drama entre o espírito heróico e o espírito crítico. O poema de Camões é um espelho dessa luta: um punhado de verdades numa armação de mentira. Coexistência livre dos dois planos" - escreve agora em "O paradoxo português" Ora, $\mathrm{Ca}-$ mões - e muitos se esquecem disso - viveu e escreveu na encruzilhada de uma febre heróica em falência e um espírito crítico nascente. "Esse genial equi íbrio poético retardatário e o novo espírito crítico durou um instante como certos efeitos de luz no rico entardecer do verão. Era muito difícil conciliar a Renascença e a AntiRenascença; D. Sebastião e o livre Juizo da realidade nova" Camões o fez. E a obra de Fidelino é uma demonstração dessa tese. Ainda que a crítica moderna procure desvincular a obra de sua realidade existencial, o poema camoniano não pode ser desarticulado de um contexto histórico e cultural - talvez o momento mais crítico da história da consciência ocidental. A ardência heróica dos descobrimentos marítimos; o estudo científico da natureza física e antropológica - conseqüentemente a curiosidade intelectual e o gosto de informar; e, logo a seguir, o espírito crítico ensombrecido pela ideologia recristianizadora da Contra-Reforma, tudo isso, esquematizado numa carpintaria mitológica dessacralizaula pelo Poeta, invadiu violentamente o poema camoniano. As contradições da epo- 
péia portuguesa são as contradições de sua época. Abstrair de'as conduzir-nos-ia a uma visão incompleta e superficial de sua obra épica.

Um pouco avesso à crítica de fontes, ou melhor, temeroso de que o sempre incompleto conhecimento das outras literaturas pudesse conduzi-'o a ilações arbitrárias" - como ele mesmo diz - F.F. deixou-nos ainda um importante estułlo acerca da presença de Camões na obra de Lope de Vega, publicado em Ultimas aventuras, em 1941 ; e avesso ainda à exegese que normalmente sufoca a intuição crítica, o Mestre de Alva ade, que em todos esses anos manteve à margem de sua investigação a poesia lírica do Poeta, resolveu encerrar o seu tirocínio camoniano com duas páginas e meia a propósito do velho enigma dos "olhos Gonçalves" "Os extensos e poderosos estudos, a que este passo camoniano tem dado pretexto, exemplificam bem a tirania da erulição sobre a intuição" E, sobrepondo esta àquela, Fidelino fez descansar em paz a tão controvertida passagem do vilancete de Camões. Estávamos, prec.samente, em 1953: iniciava-se o seu segundo exílio; Fidelino punha um ponto final no seu longo e fraternal convívio com o vate quinhentista, rematando melancolicamente: "Por agora as forças não dão para mais. Os médicos estudam-me e não me curam.

Era verdade. A medicina foi impotente e acabou superada pela grandeza do homem, que desafiou todos os revezes cruéis de uma dramática existência física; o seu espírito se sobrepôs altaneiro à estúpida realidade corpórea, amparado pela mão e pelo amor de uma esposa santa, porém estranhamente fortalecido por uma filosofia sui-gêneris, onde não figurava o ingrediente teológico e não raro um humanismo olímpico, erasmiano, cosmológico, vinha temperado por acentos de ironia e ceticismo. Quando, em junho de 1963, desfrutamos de um convívio muito íntimo residinito na sua casinha tão poética da rua Duarte Lobo no Alvalade, com ele aprendi outras lições de vida e entre elas a de que o homem consegue viver superiormente sem o exercício da palavra: Fidelino falava com os o hos; Fidelino criou uma linguagem transcendente, uma metalinguagem, que vinha do seu pensamento para o nosso, sublimada pelos lábios de sua tão devotada Companheira. Falou, sem o recurso da palavra, até o instante final em que devia deixar o mundo.

E e'e, que no último símbolo de Um Colecionador de angústias acabou por escrever uma verdadeira filosofia do crepúsculo, exaltando a nostalgia das horas vespertinas e abominando a frieza da inflexível Aurora, não pôde entretanto partir como partira Quixote, carregado de experiências: ao anoitecer Fidelino despediu-se na manhã de 10 de março de 1967 , deixando um clarão muito intenso nos corações amigos. Fidelino despediu-se no momento em 
que desejou a Morte, ilusoriamente convencido de que no Além, a relembrar o ve'ho mito isoldiano - já o esperava o coração da dedicada Companheira. Mas só dez dias depois é que ambos se encontraram.

São Paulo, 2 de novembro de 1973.

Segismundo Spina 